\title{
Role of whole brain radiotherapy in the management of infratentorial metastases from lung and breast cancer
}

\author{
Bernardo Cacho-Díaz (ํ) ${ }^{1}$, Alejandra Alvarez-Alvarez ${ }^{1}$, Karen Salmerón-Moreno (i) ${ }^{1}$, \\ Oscar Rodríguez-Mayoral ${ }^{2}$, Bernardino Gabriel Santiago-Concha ${ }^{3}$, Oscar G. Arrieta Rodríguez ${ }^{4}$ \\ ${ }^{1}$ Neuro-oncology Unit, Instituto Nacional de Cancerología, Mexico City, Mexico
${ }^{2}$ Palliative Care Unit, Instituto Nacional de Cancerología, Mexico City, Mexico
Radiation Oncology Unit, Instituto Nacional de Cancerología, Mexico City, Mexico
${ }^{4}$ Thoracic Oncology Unit, Instituto Nacional de Cancerología, Mexico City, Mexico
}

\section{ABSTRACT}

Background: Brain metastases (BM) occur in almost one third of patients with systemic malignancies. Only a small number of studies focus on infratentorial location and whole brain radiotherapy (WBRT) as the main non-surgical management. The aim of the study was to compare the prognosis of patients treated with WBRT among patients with supra- or infratentorial lesions. Materials and methods: At a single center, 263 patients with either breast (BC) or lung (LC) cancer, that had developed BM and received treatment with WBRT, were analyzed during an 8-year period.

Results: A total of 152 patients with $B C$ and 111 with $L C$ were analyzed, median age at the time of BM was 50.7 years, systemic activity other than BM was detected in $91 \%$. Newly diagnosed BM were supratentorial in $40 \%$, infratentorial in $10 \%$ and $51 \%$ in both locations. Median overall survival was 13 months (95\% Cl: 11.1-14.8 months), without significant difference between supra- or infratentorial location. WBRT alone was administered in $79 \%$ of patients, whereas WBRT with chemtoreapy was provided for $21 \%$.

Conclusion: In patients with BM from LC or BC that were not candidates for surgical resection, palliative WBRT appears to be equally effective in those with supra- or infratentorial locations.

Key words: radiotherapy; palliative care; whole-brain radiotherapy; lung cancer; breast cancer; infratentorial

Rep Pract Oncol Radiother 2021;26(4):512-517

\section{Introduction}

Brain metastases (BM) are an ominous complication of cancer that occurs in up to $30 \%$ of patients with systemic malignancies $[1,2]$. Lately a raise in the incidence of $\mathrm{BM}$ has been appreciated, this might be due to increased awareness by oncologists, further imaging surveillance and fitter treatments that boost overall survival $[2,3]$. Among all types of tumors, the ones that most frequently develop BM are lung cancer (LC) and breast cancer (BC) [4].

Although the location of BM vary in every patient, they can be broadly sub-divided as either supratentorial (above the tentorium cerebelli - involving the cerebrum) or infratentorial (between tentorium cerebelli and foramen magnum - involving the cerebellum and brainstem), consistently, the supratentorial compartment displays the majority of the lesions [5]. On the other hand, it has been 
proposed that patients with metastases located in the infratentorial compartment have worse outcome owing to the fragile structures that are contained in this region and the cumbersome properties of this location, such as the osseous boundaries (the clivus anteriorly, the temporal bones anterolaterally and the occipital bone posteriorly-inferiorly) that behave like a protective sanctuary preventing patients that develop BM in this location from receiving appropriate doses of radiation. Besides, fragile structures, such as the brainstem and the cranial nerves, futher complicate radiation to this region $[5,6]$.

Whole brain radiation therapy (WBRT) has been a cornerstone tool for the management of $\mathrm{BM}$; although it has been associated with adverse effects, the effectiveness of this therapy has been validated by multiple clinical trials, and when used in the proper setting, the benefits outweigh the potential unwanted effects $[7,8]$. In the palliative care context, this therapy is primarily offered to patients with BM that are not suitable for surgical resection [3].

Concomitant treatment of solid tumors with WBRT along with systemic therapy has been studied elsewhere $[8,9]$; albeit, to our current knowledge, there is no convincing evidence that simultaneous treatment with systemic therapy and WBRT significantly improves outcomes. Furthermore, modern literature concentrates on surgical and stereotactic radiosurgery approaches [6], whereas only a small number of studies focus on infratentorial location and WBRT as the main nonsurgical management [5].

The aim of the present study was to determine if the effectiveness of WBRT for palliating infratentorial metastases was non-inferior to the effectiveness of WBRT for supratentorial metastases, in patients with BC and LC.

\section{Materials and methods}

This study was designed as a retrospective, single center study. All definitions and criteria were specified before data collection. Inclusion criteria for patients were: 1 . $\geq 18$ years of age; 2 . pathology-confirmed diagnosis of primary LC or BC; 3 . new diagnosis of BM between June 1, 2010 and June 30, 2018; 4. Patients must have received WBRT with conventional megavoltage external beam radiotherapy, administered with a linear accelerator (energy 6MV) or with a cobalt bomb (1.25 MV); 5. T1-contrast MRI obtained prior to WBRT must be available; 6 . Patients must have attended a neuro-oncology (NeOn) consultation. Exclusion criteria were: 1 . incomplete medical record; 2 . diagnosis of neoplastic meningitis; 3 . previous treatment for $\mathrm{BM} ; 4$. an alternate neurological diagnosis.

Collected characteristics that were obtained from medical charts were: age, sex, date of primary cancer diagnosis, date of first BM diagnosis, date of last follow-up or death, presence of systemic metastasis (considered as any metastasis other than a BM), total number of BM, localization (supratentorial, infratentorial - which included the cerebellum and brainstem regions - and side), modality of treatment - either WBRT or WBRT with chemotherapy (temozolamide) - and score on the Karnofsky Performace Status scale (KPS) at the time of BM diagnosis.

\section{Statistical analysis}

Analyses comparing BC to LC were performed using the $\chi^{2}$ test, T-test, or log-rank test according to the analyzed variable. Survival comparisons were performed by using Kaplan-Meier curves, and comparisons among groups were evaluated with a Log-Rank test; a predetermined $\mathrm{p}$ value $<0.05$ was set to be statistically significant. All statistical analyses were performed using IBM SPSS Statistics, version 25 (IBM Corp. Armonk, N.Y., USA).

\section{Results}

A total of 296 patients were sent to the $\mathrm{NeOn}$ unit for assessment. 33 patients were excluded, 16 because they had been treated by surgical resection and 17 because they had received stereotactic radiosurgery treatment; accordingly, only 263 patients were considered for the final analysis. Female sex predominated with 221 (84\%) patients; at the time the analysis was performed $21(8 \%)$ patients were still alive. The primary tumor was BC in 152 (58\%) patients and LC in 111 patients (42\%); the most frequent histological types were HER2+ and non-small cell (NSCLC), respectively. Median time from the diagnosis of primary tumor to diagnosis of BM was 13 months (Range 0-354 months), most patients had systemic metastases other than BM (91\%), other general characteristics of the population are described in Table 1. 
Table 1. General characteristics for patients with breast or lung cancer who developed brain metastases

\begin{tabular}{|c|c|c|c|c|c|}
\hline \multicolumn{2}{|c|}{ Primary cancer } & $\begin{array}{c}\text { Breast } \\
(n=152)(\%)\end{array}$ & $\begin{array}{c}\text { Lung } \\
(n=111)(\%)\end{array}$ & $\begin{array}{c}\text { Total } \\
(n=263)(\%)\end{array}$ & p-value \\
\hline \multirow{2}{*}{ Sex } & Female & $152(100)$ & $69(62)$ & $221(84)$ & \multirow{2}{*}{${ }^{*}<0.0001$} \\
\hline & Male & - & $42(38)$ & $42(16)$ & \\
\hline \multicolumn{2}{|c|}{ Systemic metastases } & $144(95)$ & $95(86)$ & 239 (91) & ${ }^{*}<0.01$ \\
\hline \multicolumn{2}{|c|}{ Contralateral lung } & $68(45)$ & $21(19)$ & $89(34)$ & ${ }^{*}<0.0001$ \\
\hline \multicolumn{2}{|c|}{ Liver metastases } & $52(34)$ & $25(23)$ & $77(29)$ & ${ }^{*} 0.027$ \\
\hline \multicolumn{2}{|c|}{ Bone metastases } & $88(58)$ & $69(62)$ & $157(60)$ & ${ }^{*} 0.28$ \\
\hline \multicolumn{2}{|c|}{$\begin{array}{l}\text { Median age at cancer diagnosis } \\
\text { years (Min-Max) }\end{array}$} & $46.9(25-75)$ & $57.4(31-85)$ & $50.7(25-85)$ & ${ }^{* *} \dagger<0.0001$ \\
\hline \multicolumn{2}{|c|}{$\begin{array}{l}\text { Median age at BM diagnosis } \\
\text { years (Min-Max) }\end{array}$} & $53.9(30-79)$ & $58.1(31-85)$ & $55.1(30-85)$ & ${ }^{* *}++0.008$ \\
\hline \multicolumn{2}{|c|}{$\begin{array}{l}\text { Median time from initial cancer diagnosis } \\
\text { to BM diagnosis } \\
\text { months (Min-Max) }\end{array}$} & $33.5(0-354)$ & $1(0-100)$ & $13(0-354)$ & **十†ナ<0.0001 \\
\hline
\end{tabular}

p-value was calculated with the following statistical tests: ${ }^{*} \chi^{2}$;*T test; ${ }^{* * *}$ Log-rank; Skewness: $\uparrow 0.2,+\dagger 0.1,+\dagger+2.4 ; \mathrm{Cl}$ - confidence interval

Subgroup analysis and survival outcomes for the type of cancer, number of BM, side, presence of systemic metastasis, KPS, and time of BM development from primary tumor diagnosis according to supratentorial, infratentorial, or both are available at Table 2 . There were no statistically significant differences in median overall survival (OS) after diagnosis of BM among subgroups. OS was 13 months (95\% CI: 11-14 months) for all patients; 14 months for those with BM exclusively at the supratentorial compartment; 14 months for those with exclusively infratentorial BM; and 13 months for patients with supra- and infratentorial BM (Fig. 1). Supplementary Table 1 compares OS among BC subtypes.

WBRT alone was administered in a total of 208 patients (79\%), among this group, OS after BM diagnosis was of 12 months (95\% CI: 10-13 months); 12 months for patients with either supratentorial or supra- and infratentorial BM; and only 8 months (95\% CI: 2.5-13.5 months) for patients with exclusively infratentorial BM.

Meanwhile, 55 patients (20.9\%) received WBRT followed by chemotherapy, in this group, median OS after BM diagnosis was 24 months (95\% CI: 18-29 months); 26 months for patients with either supratentorial-only or infratentorial-only BM; and 20 months for patients with BM in both compartments. These results can be found in Table 3 .

The most common radiation regimen administered was a total of 30 Gy distributed in 10 frac- tions, additional information regarding radiotherapy treatment is available in Supplementary Table 2.

\section{Discussion}

In our sample of 263 patients, OS was not significantly different between patients with infratentorial $\mathrm{BM}$ and patients with supratentorial BM. Furthermore, we did not identify significant differences in OS according to affected side, number of BM, presence of other systemic metastases, KPS, or time elapsed before development of BM.

With improved radiation techniques, stereotactic radiosurgery is becoming a frequent treatment modality for BM $[9,10]$. However, as our results suggest, OS in patients with infratentorial $\mathrm{BM}$ is similar, even in those treated previously with SRS or surgery [7], suggesting that WBRT could be considered a palliative treatment modality for these patients. Previous reports have considered radiobiological models providing non-uniform irradiation as a treatment modality in these patients $[11,12]$. However, our study provides information suggesting these approaches might not be needed when a homogeneous dose is planned an administered as WBRT.

It is important to consider that concomitant and subsequent systemic therapies that are not included in this analysis represent a major bias and might be a significant confounding variable for overall survival. As well, the retrospective design of 
Table 2. Subgroup analysis and survival outcomes according to brain metastases localization

\begin{tabular}{|c|c|c|c|c|c|c|c|c|}
\hline \multicolumn{2}{|l|}{ Subgroup } & $\begin{array}{l}\text { Supratentorial } \\
n=105(40 \%)\end{array}$ & $\begin{array}{l}\text { Infratentorial } \\
n=25(10 \%)\end{array}$ & $\begin{array}{c}\text { Both } \\
n=133 \\
(51 \%)\end{array}$ & $\begin{array}{l}\text { Total } \\
n=263 \\
(100 \%)\end{array}$ & p-value & $\begin{array}{c}\text { MOS } \\
\text { months } \\
(95 \% \mathrm{CI})\end{array}$ & $\begin{array}{c}\log -\operatorname{Rank} \\
\mathrm{p}\end{array}$ \\
\hline \multirow{2}{*}{ Type of cancer } & Lung & $54(51.4)$ & $5(20)$ & $52(39.1)$ & $111(42.2)$ & \multirow{2}{*}{${ }^{*} 0.01$} & $13(10.7-15.2)$ & \multirow{2}{*}{0.64} \\
\hline & Breast & $51(48.6)$ & $20(80)$ & $81(60.9)$ & $152(57.8)$ & & $13(9.9-16.1)$ & \\
\hline \multirow{3}{*}{$\begin{array}{l}\text { Number of } \\
\text { BM }\end{array}$} & 1 & $55(52.4)$ & $16(64)$ & $2(1.5)$ & $73(27.8)$ & \multirow{3}{*}{${ }^{*}<0.0001$} & $14(10.7-17.3)$ & \multirow{3}{*}{0.15} \\
\hline & $2-3$ & $33(31.4)$ & $7(28)$ & $27(20.3)$ & $67(25.5)$ & & $11(6.9-15)$ & \\
\hline & $>3$ & $17(16.2)$ & $2(8)$ & $104(78.2)$ & $123(46.8)$ & & $13(10.3-15.7)$ & \\
\hline \multirow{4}{*}{$\begin{array}{l}\text { Location by } \\
\text { side }\end{array}$} & Left & $32(30.5)$ & $5(20)$ & $11(8.3)$ & $48(18.3)$ & \multirow{4}{*}{${ }^{*}<0.0001$} & $14(9-18.9)$ & \multirow{4}{*}{0.98} \\
\hline & Right & $37(35.2)$ & $11(44)$ & $3(2.3)$ & $51(19.4)$ & & $12(8.1-15.8)$ & \\
\hline & Both & $35(33.3)$ & $5(20)$ & $119(89.5)$ & $159(60.5)$ & & $13(10.6-15.3)$ & \\
\hline & Middle line & $1(1)$ & $4(16)$ & - & $5(1.9)$ & & $13(10.8-15.1)$ & \\
\hline \multirow{2}{*}{$\begin{array}{l}\text { Systemic } \\
\text { metastasis }\end{array}$} & Active & $96(91.4)$ & $24(96)$ & $119(89.5)$ & $239(90.9)$ & \multirow{2}{*}{${ }^{*} 0.56$} & $13(11.1-14.8)$ & \multirow{2}{*}{0.13} \\
\hline & Inactive & $9(8.6)$ & $1(4)$ & $14(10.5)$ & $24(9.1)$ & & $15(8.9-21)$ & \\
\hline \multirow{6}{*}{$\begin{array}{l}\text { KPS at BM } \\
\text { diagnosis }\end{array}$} & 40 & - & - & $2(1.5)$ & $2(0.8)$ & \multirow{6}{*}{${ }^{*} 0.06$} & $5(-)$ & \multirow{6}{*}{0.42} \\
\hline & 50 & - & $2(8)$ & $8(6)$ & $10(3.8)$ & & $19(0-38)$ & \\
\hline & 60 & $2(1.9)$ & $1(4)$ & $6(4.5)$ & $9(3.4)$ & & $6(3-8.9)$ & \\
\hline & 70 & $15(70)$ & $3(12)$ & $30(22.6)$ & $48(18.3)$ & & $12(9.4-14.5)$ & \\
\hline & 80 & 44 (41.9) & $11(44)$ & 37 827.8) & $92(35)$ & & $12(9.3-14.6)$ & \\
\hline & 90 & 44 (41.9) & $8(32)$ & $50837.6)$ & $105(38.8)$ & & 15 (10.7-19.2) & \\
\hline \multirow{7}{*}{$\begin{array}{l}\text { Time of BM } \\
\text { development }\end{array}$} & $\begin{array}{l}\text { At } \\
\text { diagnosis }\end{array}$ & $23(21.9)$ & $3(12)$ & $30(22.6)$ & $56(21.3)$ & \multirow{7}{*}{${ }^{*} 0.08$} & $14(10.4-17.53)$ & \multirow{7}{*}{0.9} \\
\hline & $\begin{array}{l}1-12 \\
\text { months }\end{array}$ & $33(31.4)$ & $5(20)$ & $34(25.6)$ & $72(27.4)$ & & $11(7.9-14)$ & \\
\hline & $\begin{array}{l}>12-24 \\
\text { months }\end{array}$ & $16(15.2)$ & $2(8)$ & $20(15)$ & $38(14.4)$ & & $13(9.2-16.7)$ & \\
\hline & $\begin{array}{l}>24-36 \\
\text { months }\end{array}$ & $9(8.6)$ & $7(28)$ & $7(5.3)$ & $23(8.7)$ & & $15(10.5-19.4)$ & \\
\hline & $\begin{array}{l}>36-48 \\
\text { months }\end{array}$ & $2(1.9)$ & $1(4)$ & $785.3)$ & $1083.8)$ & & $3(1.9-4)$ & \\
\hline & $\begin{array}{l}>48-60 \\
\text { moths }\end{array}$ & $3(2.9)$ & $2(8)$ & $583.8)$ & $10(3.8)$ & & $8(2.8-13.1)$ & \\
\hline & $\begin{array}{l}>60 \\
\text { months }\end{array}$ & $19(18.1)$ & $5(20)$ & $30(22.6)$ & $54(20.5)$ & & $17(12-21.9)$ & \\
\hline \multicolumn{2}{|c|}{ MOS months ( $95 \% \mathrm{Cl}$ ) } & $14(10.5-17.4)$ & $14(9.1-18.8)$ & $\begin{array}{c}13(10.6- \\
15.3)\end{array}$ & $\begin{array}{c}13(11.1- \\
14.8)\end{array}$ & - & - & 0.19 \\
\hline
\end{tabular}

p-value was calculated with the following statistical tests: ${ }^{2} \chi^{2},{ }^{* *} \mathrm{~T}$ test, ${ }^{* * *}$ Log-rank; MOS — median overall survival after BM diagnosis; BM — brain metastasis; KPS — Karnofsky Performance Status; WBRT — whole brain Radiotherapy; CTX — chemotheraphy

this study confers some limitations to the collected data. In order to address this limitation, every electronic medical chart and imaging studies were reevaluated by an experienced neuro-radiologist and a neuro-oncologist, and variable definitions were stablished a priori. Beside this caveat, the study was performed by collecting data from a single center; therefore, a selection bias should also be considered.

The historic affirmation that infratentorial BM have a worse prognosis than supratentorial ones
[5] could be reconsidered in the palliative setting in the modern era, probably due to advances in systemic treatments including WBRT. Our results suggest that WBRT continues to be a useful tool in the management of patients with brain metastasis, and that its effectiveness in the palliative setting is similar for patients with infratentorial BM; also, chemotherapy administered after WBRT appears to provide a longer overall survival; however we consider that these results should be corroborated by future prospective studies. 


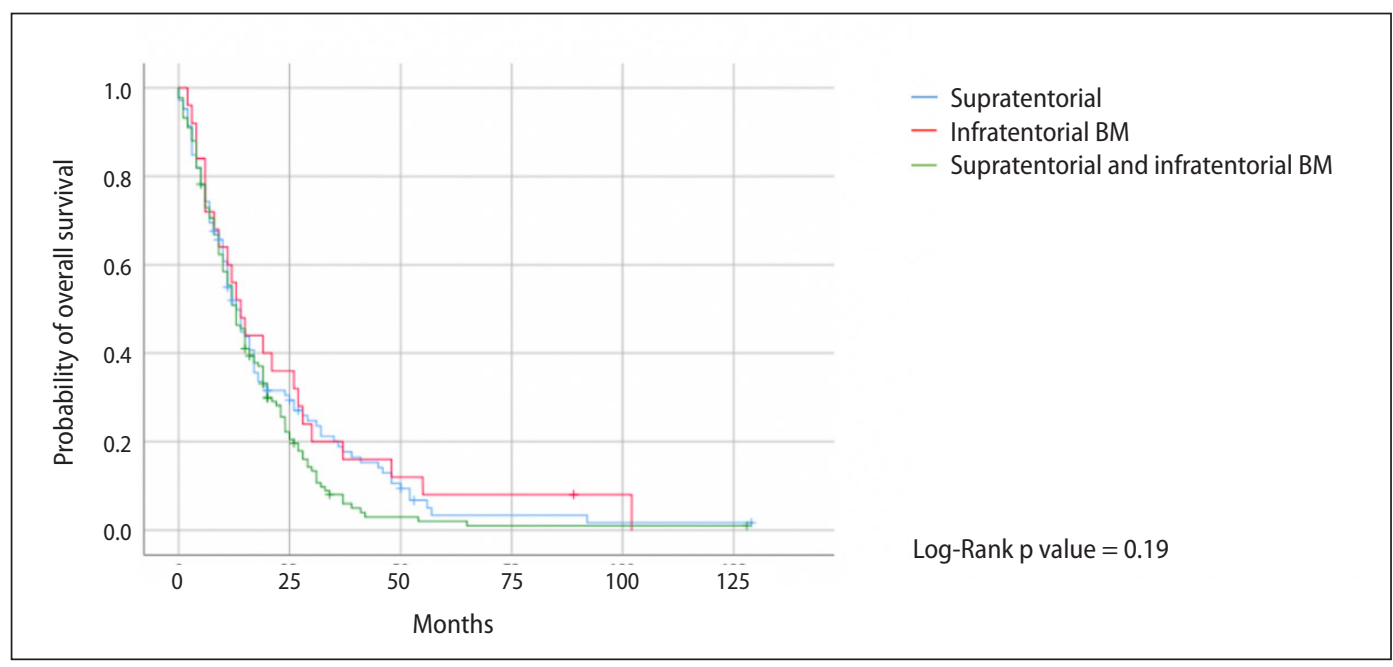

Figure 1. Kaplan-Meier curves for overall survival according to BM location (supratentorial vs. infratentorial vs. both)

Table 3. Survival outcomes for brain metastases according to modality of treatment and localization

\begin{tabular}{|c|c|c|c|c|c|}
\hline \multirow{2}{*}{ Localization /Treatment } & \multicolumn{2}{|c|}{$\begin{aligned} & \text { WBRT } \\
n= & 208(79 \%)\end{aligned}$} & \multicolumn{2}{|c|}{$\begin{array}{c}\text { WBRT/CTX } \\
(n=55)(20.9)\end{array}$} & \multirow{2}{*}{ Log-rank } \\
\hline & n (\%) & $\begin{array}{l}\text { MOS in months } \\
(95 \% \mathrm{Cl})\end{array}$ & n (\%) & $\begin{array}{l}\text { MOS in months } \\
(95 \% \mathrm{Cl})\end{array}$ & \\
\hline $\begin{array}{l}\text { Supratentorial } \\
n=105(40 \%)\end{array}$ & $89(84.8)$ & $12(9.8-14.1)$ & $16(15.2)$ & $26(14.2-37.6)$ & 0.253 \\
\hline $\begin{array}{l}\text { Infratentorial } \\
\mathbf{n}=\mathbf{2 5}(\mathbf{1 0 \% )}\end{array}$ & $14(56)$ & $8(2.5-13.5)$ & $11(44)$ & $26(17.3-34.6)$ & 0.019 \\
\hline $\begin{array}{l}\text { Both } \\
n=133(51 \%)\end{array}$ & 105 (78.9) & $12(9.8-14.1)$ & $28(21.1)$ & $20(16.8-23.1)$ & 0.122 \\
\hline $\begin{array}{l}\text { Total } \\
\mathrm{n}=263(100 \%)\end{array}$ & $208(79)$ & $12(10.5-13.4)$ & $55(20.9)$ & $24(18.1-29.8)$ & 0.009 \\
\hline
\end{tabular}

MOS - median overall survival after BM diagnosis; WBRT — whole brain radiotherapy; CTX — chemotherapy

\section{Conclusion}

In patients with $\mathrm{LC}$ or $\mathrm{BC}$ that develop $\mathrm{BM}$ and are not candidates for surgical resection, WBRT appears to be effective for the palliation of BM, irrespective of their supra- or infratentorial location.

\section{Conflict of interest}

No conflicts of interest are reported by any author.

\section{Funding}

The present study was not funded by any grant, particular, or public sponsor.

None declared.

\section{Acknowledgements}

\section{Ethical approval and consent to participate}

This study was an observational retrospective study that did not jeopardize patient's clinical management or identity. Therefore, ethical approval and consent to participate were not required

\section{Consent for publication}

All authors approved the final version of this manuscript.

\section{Data sharing statement}

All data generated and analyzed during this study are included in this published article. Datasets are available through the corresponding author on reasonable request. 


\section{References}

1. Gállego Pérez-Larraya J, Hildebrand J. Brain metastases. Handb Clin Neurol. 2014; 121: 1143-1157, doi: 10.1016/B978-0-7020-4088-7.00077-8, indexed in Pubmed: 24365409.

2. Suh JH, Kotecha R, Chao ST, et al. Current approaches to the management of brain metastases. Nat Rev Clin Oncol. 2020; 17(5): 279-299, doi: 10.1038/s41571-019-0320-3, indexed in Pubmed: 32080373.

3. Moravan MJ, Fecci PE, Anders CK, et al. Current multidisciplinary management of brain metastases. Cancer. 2020; 126(7): 1390-1406, doi: 10.1002/cncr.32714, indexed in Pubmed: 31971613.

4. Nayak L, Lee EQ, Wen PY. Epidemiology of brain metastases. Curr Oncol Rep. 2012; 14(1): 48-54, doi: 10.1007/ s11912-011-0203-y, indexed in Pubmed: 22012633.

5. Kancharla P, Ivanov A, Chan S, et al. The effect of brain metastasis location on clinical outcomes: A review of the literature. Neurooncol Adv. 2019; 1(1):vdz017, doi: 10.1093/ noajnl/vdz017, indexed in Pubmed: 32642653.

6. Sunderland GJ, Jenkinson MD, Zakaria R. Surgical management of posterior fossa metastases. J Neurooncol. 2016; 130(3): 535-542, doi: 10.1007/s11060-016-2254-2, indexed in Pubmed: 27619980.

7. Tsao MN, Xu W, Wong RKs, et al. Whole brain radiotherapy for the treatment of newly diagnosed multiple brain metastases. Cochrane Database Syst Rev. 2018; 1: CD003869, doi: 10.1002/14651858.CD003869.pub4, indexed in Pubmed: 29365347.
8. Arrieta O, Villarreal-Garza C, Zamora J, et al. Long-term survival in patients with non-small cell lung cancer and synchronous brain metastasis treated with whole-brain radiotherapy and thoracic chemoradiation. Radiat Oncol. 2011; 6: 166, doi: 10.1186/1748-717X-6-166, indexed in Pubmed: 22118497.

9. Sato $Y$, Yamamoto M, Serizawa T, et al. Stereotactic radiosurgery for patients with multiple brain metastases: a casematched study comparing treatment results for patients with 2-9 versus 10 or more tumors. J Neurosurg. 2014; 121 Suppl(3): 16-25, doi: 10.3171/2014.8.GKS141421, indexed in Pubmed: 25434933.

10. Qie S, Li Y, Shi HY, et al. Stereotactic radiosurgery (SRS) alone versus whole brain radiotherapy plus SRS in patients with 1 to 4 brain metastases from non-small cell lung cancer stratified by the graded prognostic assessment: A meta-analysis (PRISMA) of randomized control trials. Medicine (Baltimore). 2018; 97(33): e11777, doi: 10.1097/MD.0000000000011777, indexed in Pubmed: 30113464.

11. Nicosia L, Figlia V, Mazzola R, et al. Repeated stereotactic radiosurgery (SRS) using a non-coplanar mono-isocenter (HyperArc ${ }^{\mathrm{TM}}$ ) technique versus upfront whole-brain radiotherapy (WBRT): a matched-pair analysis. Clin Exp Metastasis. 2020; 37(1): 77-83, doi: 10.1007/s10585-01910004-3, indexed in Pubmed: 31691873.

12. Bender ET, Tomé WA. Distribution of brain metastases: implications for non-uniform dose prescriptions. Br J Radiol. 2011;84(1003): 649-658, doi: 10.1259/bjr/30173406, indexed in Pubmed: 21697413. 